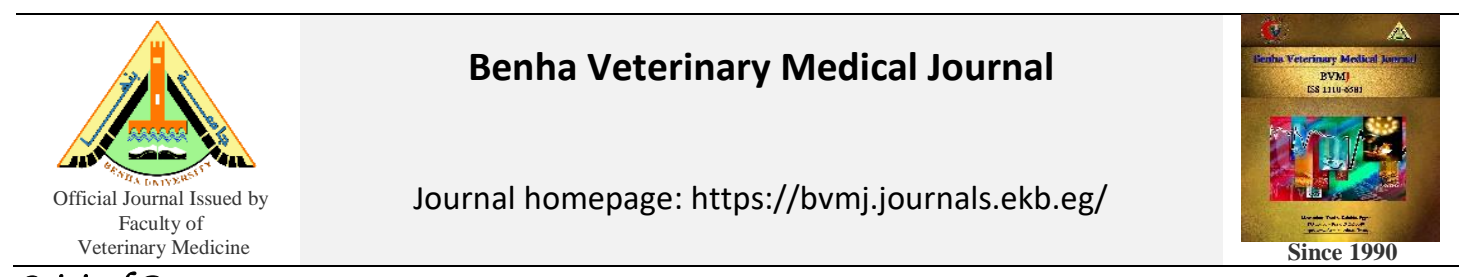

Original Paper

\title{
Biofilm formation by Staphylococcus aureus isolated from some Egyptian meat processing plants and hotels' environments with special reference to its sensitivity to sanitizers
}

Ahmed M.A. Hamad, Saad M. Saad, Hemmat M.I. Mohamed

Department of Food Hygiene, Faculty of Veterinary Medicine, Benha University, Egypt.

\begin{tabular}{|c|c|}
\hline ARTICLE INFO & ABSTRACT \\
\hline $\begin{array}{l}\text { Keywords } \\
\text { Biofilm } \\
\text { Cross-contamination } \\
\text { Food processing } \\
\text { environment } \\
\text { Sanitizers. } \\
\text { Staphylococcus aureus }\end{array}$ & $\begin{array}{l}\text { Staphylococcus aureus (Staph. aureus)is Gram-positive bacterium commonly associated with } \\
\text { food poisoning diseases. This pathogen is responsible for food-borne illnesses outbreaks } \\
\text { associated with the consumption of food especially meat products. The aims of this study were } \\
\text { to evaluate the ability of Staph. aureus recovered from food contact surfaces in meat processing } \\
\text { environment of Egypt for biofilm formation and to test their susceptibility to the commercially } \\
\text { used sanitizers including Quaternary ammonium compounds (QACs, 200ppm), Sodium } \\
\text { hypochlorite ( } 200 \mathrm{ppm} \text { ) and Iodine }(2.5 \%) \text {. The ability of isolates for biofilm formation and } \\
\text { their sensitivity to sanitizers were investigated in } 96 \text {-well flat bottom microtiter plates. Twelve } \\
\text { strains were obtained from } 120 \text { food contact surfaces (FCS) using standard microbiological } \\
\text { techniques. All isolated strains } 100 \%(12 / 12) \text { manifested high ability to form biofilm, which } \\
\text { was classified as a strong type. Further, the application of QACs, Sodium hypochlorite and } \\
\text { iodine generated a reduction of ( } 76.77 \%) \text {, ( } 71.38 \%) \text { and (15.84\%) in the biofilm formation, } \\
\text { respectively. Conclusively, all sanitizers were not } 100 \% \text { efficient in removing the biofilm } \\
\text { formed by isolated Staph. aureus on polypropylene. Therefore, vigilant food safety practices } \\
\text { need to be implemented in the meat processing environment, at meat processing plant and food } \\
\text { services establishments, especially for FCS to prevent foodborne infections and intoxications } \\
\text { due to } S \text {. aureus contamination from biofilms. }\end{array}$ \\
\hline
\end{tabular}

\section{INTRODUCTION}

In food industry, bacterial resistance to environmental stresses including cleaning, disinfection, and inhibition, increased by biofilms enabling these microorganisms to remain on surfaces and processing equipment, compared to planktonic cells (Avila-Novoaet al., 2018).

Biofilms can be defined as aggregation of bacteria embedded in a self-produced extracellular matrix of exopolysaccharides (EPS), proteins and some macromolecules such as DNA (Neopane et al., 2018).

Staph. aureus can develop biofilm in four stages: attachment, microcolony formation, maturation and detachment. The extracellular matrix of exopolysaccharides (EPS) is one of the most vital substances that essential for cellular encasement and community function in different stages (Miao et al., 2019).Staph. aureus have the ability to form biofilms on both biotic and abiotic surfaces along the food production chain and their biofilms growth enhanced by various processing methods encountered in the food industry, such as suboptimal temperatures, improper disinfection or a combination of salt and glucose (Galié et al., 2018).

The ability of Staphylococcus spp. to form biofilms is one of the virulence factors that facilitate adhesion and colonization, a fact leading to recurrent or persistent infections (Felipe et al., 2019).
Meat products can be contaminated with Staph. aureus from infected food handlers, which can be asymptomatic carriers during slaughtering and processing of livestock or by cross contamination during food preparation due to its ability to attach to surfaces and forming biofilms (Giaouris and Simões, 2018).

In view of this, it becomes important to reduce the bacterial burden in biofilms by controlling cross-contamination of surfaces of meat processing equipment using sanitizers. Quaternary ammonium salts (QAC) is one of the most used classes of disinfectants, with wide application in hospital environments, water treatment and food, due to their relatively low toxicity to humans and animals and their very wide antimicrobial spectrum (Constantin et al., 2016). Further, Sodium hypochlorite $(\mathrm{Na} \mathrm{OCl})$ is an antimicrobial agent frequently and widely used in the food industry as an effective biocide for the control of microbial contamination (Kim et al., 2016),because foodborne bacteria exhibited a wide range of susceptibility to it. However, the susceptibilities changed after biofilm formation in a straindependent manner, and the relative resistance levels changed among the isolates (Lim et al., 2017). Sodium hypochlorite had superior efficacy for controlling both planktonic and biofilm states of growth of $S$. aureus. Furthermore, the characteristic morphologic changes observed in strong biofilm formers hint at its biofilm-specific activity (Tiwari et al., 2017). Moreover, Iodine still one of the commonly used

\footnotetext{
* Corresponding author: Ahmed M.A.A.A. Hamad. Food Hygiene Department; Faculty of Veterinary Medicine; Benha University; Egypt.
} 
disinfectant products in food industry till now, it has the potential to penetrate the cell wall of microorganisms rapidly and tend to compromise proteins and nucleic acids as well as the synthesis of proteins (González-Rivaset al., 2018;Boakye, et al., 2019).

Therefore, the objectives of current study were to study the ability of Staph. aureus isolated from food contact surfaces in meat processing plants and food service establishment of Egypt to forming biofilm and to study their susceptibility to the commercially used sanitizers.

\section{MATERIAL AND METHODS}

\subsection{Sample collection}

A total of 120 scrapped swab samples were taken from food contact surfaces including different meat processing machines stainless steel and plastic surfaces, as mincer, mixer, band saw, slicer, cutting board and knifes bald, were collected from three (3) food service establishments (Five starts hotels) kitchens located in Cairo, Sharm El-sheikh and Hurghada governorates (30 samples of each), and one Meat products processing plant located in Zahraa El-Maadi, Cairo governorate (30 samples). The samples were taken from the washed, cleaned and stored stainless steel and plastic food contact surfaces. The tested area was prepared prior to sampling by measuring $\left(10 \mathrm{~cm}^{2}\right)$ using a template $(2 \times 5 \mathrm{~cm})$ disinfected by alcohol.

\subsection{Isolation and Confirmation of Staphylococcus aureus:} The procedure recommended by ISO (2003) was applied as following: $0.1 \mathrm{ml}$ from each previously prepared serial dilutions examined samples was spread with sterile glass rodover a previously dried Baird Parker media (OXIOD®, UK) with Egg yolk emulsion mixed with PotassiumTellurite solution (Biolife $₫$, UK). The plates were retained in an upright position until the inoculum was absorbed by the medium. Then the plates were incubated at an inverted position at $35^{\circ} \mathrm{Cand}$ observe after 24 to 30 hours for possible overgrowth. Presumptive colonies were counted at this time, but the count was verified at $48 \pm 4$ hours. Suspected black colonies surrounded by narrow white margin with a zone of clearing were counted to obtain the total Staph. aureus counts per square centimeter and then picked up on nutrient agar slant $(\mathrm{LabM} 囚, \mathrm{UK})$ for further confirmation. The confirmation of identified strains and coagulase positive staphylococci were confirmed by using DRY SPOT тм (Staphytect-plus) system (OXOID®).

\subsection{Biofilms formation ability of isolates}

Following Manios and Skandamis (2014), a single colony of each strain was transferred to be tested from each slant into $10 \mathrm{~mL}$ of a rich nonselective medium such as tryptic soy broth $(0.25 \%$ glucose $)$ or brain-heart infusion $(0.2 \%$ glucose) and incubated for $24 \mathrm{~h}$ at 30 or $37{ }^{\circ} \mathrm{C}$ depending on the required temperature of the microorganism. $100 \mu \mathrm{l}$ of the activated culture were transferred into $10 \mathrm{~mL}$ of fresh broth medium and incubated for $18 \mathrm{~h}$ at the corresponding temperature in order for the cells to reach the stationary phase. Accurately, 100 or $200 \mu l$ of each strain culture were transferred to a well of a sterile 96-well microtiter plate (Corning® USA) and incubated under static conditions at the required temperature $37{ }^{\circ} \mathrm{C}$ and for the desired amount of time $(4-48 \mathrm{~h})$. For quantitative assays, at least 4-8 replicates for each strain and/or treatment were used. Then planktonic bacteria were removed from each microtitre dish by aspiration of the medium from the wells.

\subsection{Staining and Quantitation of Biofilms}

Biofilm staining and quantitation was performed after Coffey and Anderson (2014).First; each well was washed by transferring 100 or $200 \mu \mathrm{l}$ of PBS in each well or by immersing the whole plate in a bath with sterile PBS in order to remove the loosely attached cells. This step was repeated for 3-5 times until the PBS of the last step was crystal clear. The microtitre plate was turned upside down in order to remove the excess PBS. The plates were left to air-dry in an airflow cabinet for $1 \mathrm{~h}$. accurately, $125 \mu \mathrm{L}$ of $0.1 \%$ crystal violet solutions was pipetted into wells. This volume ensures that the stain covered the biofilm then let sit for $10 \mathrm{~min}$. plate was inverted over waste tray to remove liquid then submerge plate into first washing tray and was rubbed the entire surface of the plate to ensure that water enters all wells. plate was removed from water, invert to remove liquid. Plate was inverted over second washing tray to remove excess water. With plate face down, pat firmly on lab mat or paper towel to remove as much water as possible. At this point, you may be able to see purple rings where biofilms have formed at the air-liquid interface on the inner surface of the plastic wells. Also, there may be biofilm on the bottom of the wells. The plate was allowed to dry for $2 \mathrm{~h}$, until all excess water is evaporated, prior to proceeding with quantitation. Stained biofilm plate was allowed to air-dry for several hours or overnight. Accurately, $150 \mu \mathrm{L}$ of $30 \%$ acetic acid were pipetted into each well. This will solubilize the biofilm. Accurately, $125 \mu \mathrm{L}$ of each sample were transferred to another 96-well optically clear, flat-bottom plate. Optical density of all samples was measured in plate at $550 \mathrm{~nm}$ using microplate reader (BioTek ${ }^{\mathrm{TM}}$ EL 800).

\subsection{Classification of biofilm forming ability by isolates}

Classification of biofilm forming ability by isolates was determined as described by Stepanovic et al. (2000).

\subsection{Sensitivity of biofilm to sanitizers \\ 2.6.1. Sanitizers preparation}

Three commercial disinfecting agents commonly used in meat processing plants and food services establishment were used as biofilms biocide and examined for their effect. A; a dual-quaternary ammonium chloride (QAC)-based sanitizer containing $4 \%$ of dodecyl dimethyl ammonium chloride and 5\% N-alkyl dimethyl benzyl ammonium chloride with a recommended sanitization concentration of $200 \mathrm{ppm}$, (SumaPack ${ }^{\circledR}$ D 10 ). B; a chlorine sanitizer containing $10.8 \%$ sodium hypochlorite with a recommended sanitization concentration of 200 ppm active chlorine (Suma ${ }^{\circledR}$ D 44, Diversey). C; a food grade iodine solution of $2.5 \%$ concentration (Microclean ${ }^{\circledR}$, Ecolab).

2.6.2. Evaluation of biofilm antimicrobial resistance was conducted according to Manios and Skandamis (2014).

\subsection{Statistical analysis:}

Statistical analysis was performed using SPSS version 22.0 software (IBM Corporation, NY, USA). Using one-way ANOVA and $t$-test. Differences between means for the variables were evaluated using repeated measures ANOVA. Post hoc Bonferroni test was used to compare the biofilm OD mean values. The level of significance was set at $p<0.05$. 


\section{RESULTS}

The overall prevalence of Staph. aureus isolated from FCS was $10 \%(12 / 120)$ as shown in figure (1). Of them, three strains were isolated from cutting board $(25 \%, 3 / 12)$, three strains from knifes $(25 \%, 3 / 12)$, two strains isolated from band saw $(16.66 \%, 2 / 12)$, two strains from mincer $(16.66 \%$, $2 / 12)$ and two strains from slicer $(16.66 \%, 2 / 12)$.

The polystyrene microtiter plate method was used to evaluate the biofilm-forming capacity of the 12 Staph. aureus strains isolated from commercial hotel kitchens and meat processing plant (Figure 2).

Each strain exhibited a distinctively different profile for biofilm formation. Their capabilities for biofilm formation were classified into three categories, weak, moderate and strong biofilm forming strain, based on absorbance (Table 1).All strains of Staph. aureus had strong capacity to produce biofilm.

The elimination potential and bactericidal effect of commercial sanitizers including quaternary ammonium compound (QAC) 200 ppm, Sodium hypochlorite $200 \mathrm{ppm}$ and Iodine $2.5 \%$ on Staph. aureus biofilm are illustrated in Figure 3.

The reduction percentages resulted from different sanitizers used in this study showed that QAC $200 \mathrm{ppm}$ generated the highest elimination potential action on Staph. aureus biofilm with reduction percent of $(76.77 \%)$, followed by chlorine $200 \mathrm{ppm}$ that yielded $71.38 \%$, reduction percentage, while iodine $2.5 \%$ had the lowest elimination power, only $15.84 \%$ reduction percentage.

Table 1 Biofilm quantification for twelve Staph aureus strains isolated in this study (Optical Density OD=550)

\begin{tabular}{ccccc}
\multicolumn{5}{l}{ study (Optical Density OD $=550$ ) } \\
\hline Strain No. & Min OD & Max. OD & Mean OD \pm SE & Strength \\
\hline 1 & 0.6310 & 1.4620 & $1.0026 \pm 0.24386$ & +++ \\
2 & 0.3090 & 0.6140 & $0.4680 \pm 0.088285$ & +++ \\
3 & 0.4770 & 0.5170 & $0.4933 \pm .01211$ & +++ \\
4 & 0.3580 & 0.7260 & $0.5316 \pm 0.10673$ & +++ \\
5 & 0.4170 & 0.9010 & $0.6690 \pm 0.140076$ & +++ \\
6 & 00.3530 & 0.6630 & $0.4990 \pm 0.08994$ & +++ \\
7 & 0.6140 & 0.9270 & $0.7523 \pm .0921635$ & +++ \\
8 & 0.4770 & 0.9010 & $0.6316 \pm 0.13516$ & +++ \\
9 & 0.2090 & 0.4280 & $0.2920 \pm 0.06854$ & +++ \\
10 & 0.3530 & 0.4090 & $0.3733 \pm 0.01789$ & +++ \\
11 & 0.3130 & 0.6270 & $0.4543 \pm 0.09198$ & +++ \\
12 & 0.3720 & 0.5790 & $0.4793 \pm 0.05987$ & +++ \\
\hline Control Negative & 0.0120 & 0.0200 & $0.0156 \pm 0.00233$ & - \\
\hline - Negative; + weak; & ++ moderate; +++ strong & &
\end{tabular}

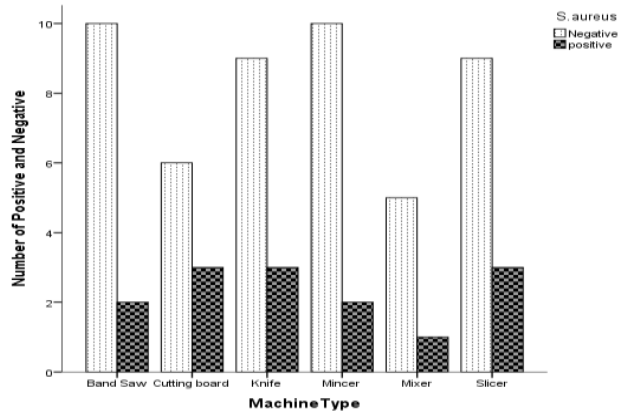

Figure 1 Prevalence of Staph. aureus on different food contact surfaces and machines types.

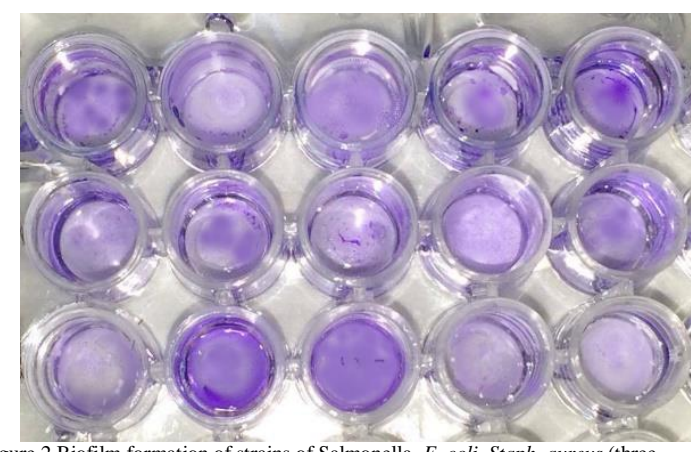

Figure 2 Biofilm formation of strains of Salmonella, E. coli, Staph. aureus (three replicates) on polystyrene microtiter plate, the biofilm was stained with $0.1 \%$ crystal violet in water. The intensity of blue color in each well indicates the potential of each strain to form biofilm under the specific conditions

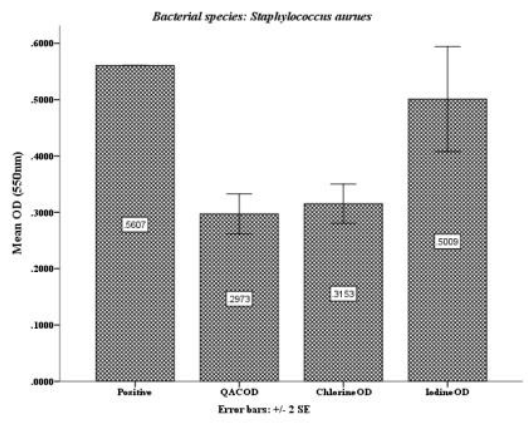

Figure 3 Effect of Commercially used sanitizers on biofilm formed by Staph. aureu

\section{DISCUSSION}

Biofilm formation process on food contact surfaces can have a detrimental effect on the microbial status of food.

As a consequence, food spoilage is likely to occur that may lead to reduced shelf life and increased risk of food poisoning from pathogens therefore, foodservice and food processing facilities are required to ensure that food safety and hygiene practices were followed by regular and appropriate decontamination and sanitation/disinfection processes because food processing area and equipment are the perfect niche for bacteria to thrive due to temperature, humidity and nutrient conditions (Myszka and Czaczyk, 2011; Limet al., 2017).

The overall incidence of Staph. aureus strains isolated from different food (meat) processing machine in both food processing plant and food service establishment was $10 \%$ $(12 / 120)$. Current results were close to the findings of previous studies (Avila-Novoa et al., 2018; Giaouris and Simões, 2018; Galié et al., 2018;Miaoet al., 2019).

In current study, the isolated Staph. aureus strains from meat processing environment in food processing and food services establishments tested for potentiality of biofilm formation. The results revealed that all isolated Staph. aureus strains possessed a high capacity for biofilm formation, but with differences in the extent of adhesion (Table 1).These results were in agreement with previous studies which confirmed the biofilm formation capability of isolated Staph .aureus strains (Avila-Novoa et al., 2018; Neopane et al., 2018; Miao et al., 2019)

Crystal violet $(\mathrm{CV})$ is a dye that binds negatively charged cell surface molecules and exopolysaccharide (EPS) and can efficiently detect bacterial presence and quantify the biomass of biofilm-forming cells and considered high- 
throughput screening method for biofilm (Peeters et al., 2008;Lim et al., 2017) (Figure 2). All bacterial isolates in current study exhibited a strong biofilm forming ability, though most of them were isolated after the routine cleaning and sanitation practices, according to sanitary standard operating procedures (SSOPs). This finding may suggest that the isolated strains acquired resistance to the routinely used disinfectant and therefore survived the disinfection treatment

Cleaning and disinfecting agents are used daily in meat plants during the routine cleaning process (Holah et al., 2002; Yang et al., 2018) to remove and prevent biofilm formation. The control of biofilm formation by Staph. aureus populations isolated from current study were assessed against three disinfecting agents that commonly used for cleaning and sanitization of equipment involving QAC, iodine and chlorinated cleaner. Most tested strains in biofilms showed different degree of susceptibility to the used biocides and these can be illustrated below.

Diluted chlorine showed low germicidal activity on experimentally tested biofilm. The activity of diluted chlorine depends on the concentration of $\mathrm{HOCl}$, the predominant form in the solution at low $\mathrm{pH}$ (4-6), which can penetrate into the microbial cell across the cell wall and membrane, and lead to damage to cellular component and injury to membrane transport capacity as well generation of active oxygen species (Virto et al., 2005; Fukuzaki 2006; Yang et al., 2018). The reduced ability of chlorine to remove biofilms was similarly reported by Melo, et al.(2014), and Kose and Yapar(2017).Also, Eriksson et al. (2017) andLinebacket al. (2018)recorded similar findingsfor the effect of Chlorine (sodium hypochlorite) on biofilm. Quaternary Ammonium Compounds have the best reduction effect on biofilm formation among the three chemical disinfectants. QAC-based sanitizer is the commonly used sanitizers in the food industries operations (Holah et al., 2002). Unlike chlorine, QACs are cationic surface-active agents where the molecules themselves are not reactants in chemical reactions (Zinchenko, et al., 2004). At recommended concentrations, QACs form mixed-micelle aggregates with hydrophobic membrane components that can solubilize the membrane and cause leakage (McBainet al., 2004; Yanget al., 2018).The reduction effects of QACs on biofilms formed by isolated pathogens were close to those obtained by Campanac et al. (2002), Ebrahimiet al. (2015) and Murrayet al. (2017)

The incomplete removal or reduction of biofilms would lead to regrowth of the remaining biofilms on surfaces, which have some living cells. These microorganisms will return to the microbial biofilm state, recovering their structures and contaminate food chains.

\section{CONCULSION}

The generated result from current study showed that Staph . aureus isolated from meat processing environment under study are capable of forming biofilms that could compromise the safety and quality of foods. Although daily cleaning and sanitizing of food contact surfaces, targeted foodborne pathogens were isolated. This comprehensive study suggests that chlorine and quaternary ammonium compounds (QACs) at 200ppm were the best among the conventional biocides in Staph. Aureus biofilms control, while iodine was with limited effect. Finally, food processing and food services establishment in Egypt should consider results of this study to prevent and control biofilms and further research will be necessary to understand biofilms regulations and to replace the biocides currently used in food processing environment.

\section{REFERENCES}

1. Avila-Novoa, M. G., Iñíguez-Moreno, M., Solís-Velázquez, O. A., González-Gómez, J. P., Guerrero-Medina, P. J. Gutiérrez-Lomelí, M. 2018. Biofilm formation by Staphylococcus aureus isolated from food contact surfaces in the dairy industry of Jalisco, Mexico. Journal of Food Quality, 1746139: 1-8.

2. Neopane, P., Nepal, H. P., Shrestha, R., Uehara, O., Abiko, Y. 2018. In vitro biofilm formation by Staphylococcus aureus isolated from wounds of hospital-admitted patients and their association with antimicrobial resistance. International journal of general medicine, 11: 25-32.

3. Miao, J., Lin, S., Soteyome, T., Peters, B. M., Li, Y., Chen, H., Harro, J. M. 2019. Biofilm Formation of Staphylococcus aureus under Food Heat Processing Conditions: First Report on CML Production within Biofilm. Scientific reports, 9(1): 19

4. Galie, S.; Garcia-Gutierrez, C.; Miguelez, E. M.; Villar, C. J., Lombo, F.2018. Biofilms in the food industry: Health aspects and control methods. Front. Microbiol., 9:1-18.

5. Giaouris, E. E., Simões, M. V. 2018. Pathogenic Biofilm Formation in the Food Industry and Alternative Control Strategies. In: Handbook of Food Bioengineering, Foodborne Diseases, First Edn. Academic Press, USA.Pp. 309-377.

6. Campanac, C., Pineau, L., Payard, A., Baziard-Mouysset, G., Roques, C. 2002. interactions between biocide cationic agents and bacterial biofilms. Antimicrobial agents and chemotherapy, 46(5): 1469-1474.

7. Murray J, Muruko T, Gill CIR, Kearney MP, Farren D, Scot $\mathrm{MG}$, et al. .2017. Evaluation of bactericidal and anti-biofilm properties of a novel surface-active organosilane biocide against healthcare associated pathogens and Pseudomonas aeruginosa biofilm. PLoS ONE 12(8): e0182624.

8. Ebrahimi A, Hemati M, Shabanpour Z, Habibian Dehkordi S, Bahadoran S, Lotfalian S., Khubani . 2015. Effects of Benzalkonium Chloride on Planktonic Growth and Biofilm Formation by Animal Bacterial Pathogens, Jundishapur J Microbiol., 8(2):e16058.

9. Melo, P., Sousa, C., Botelho, C., Oliveira R., Nader-Filho, A.. 2014. NaOCl effect on biofilm produced by Staphylococcus aureus isolated from the milking environment and mastitis infected cows. Pesquisa Veterinária Brasileira, 34(2): 109113.

10. Köse, H. and Yapar, N.. 2017. The comparison of various disinfectants' efficacy on Staphylococcus aureus and Pseudomonas aeruginosa biofilm layers. Turkish Journal of Medical Science. 47. 1287-1294.

11. Eriksson, S., Plas, M., Mörgelin, M., Sonesson, A. 2017 Antibacterial and antibiofilm effects of sodium hypochlorite against Staphylococcus aureus isolates derived from patients with atopic dermatitis. Br J Dermatol. 177: 513-521.

12. Lineback, C. B., Nkemngong, C. A., Wu, S. T., Li, X., Teska, P. J., Oliver, H. F. 2018. Hydrogen peroxide and sodium hypochlorite disinfectants are more effective against Staphylococcus aureus and Pseudomonas aeruginosa biofilms than quaternary ammonium compounds. Antimicrobial resistance and infection control, 7: 154-160

13. Lim, E. S., Lee, J. E., Kim, J. S., Koo, O. K. 2017. Isolation of indigenous bacteria from a cafeteria kitchen and their biofilm formation and disinfectant susceptibility. LWT-Food Science and Technology, 77: 376-382.

14. McBain, A. J., Ledder, G. R., Moore, L. E., Catrenich, C. L. 2004. Effects of quaternary ammonium-based formulations on bacterial community dynamics and antimicrobial 
susceptibility. Applied and Environmental Microbiology, 70(6): 3449-3456.

15. Zinchenko, A. A., Sergeyev, V. G., Yamabe, K., Murata, S., Yoshikawa K. 2004. DNA compaction by divalent cations: structural specificity revealed by the potentiality of designed quaternary di-ammonium salts. Chembiochem., 5:360-386.

16. Holah, J., Taylor, J., Dawson, D., Hall, K. 2002. Biocide use in the food industry and the disinfectant resistance of persistent strains of Listeria monocytogenes and Escherichia coli. Journal of Applied Microbiology, 92S: 111S-120S

17. Fukuzaki, S. 2006. Mechanisms of actions of sodium hypochlorite in cleaning and disinfection processes. Biocontrol Science, 11(4):147-157.

18. Virto, R., Mañas, P., Álvarez, I., Condon, S., Raso, J. 2005. Membrane damage and microbial inactivation by chlorine in the absence and presence of a chlorine-demanding substrate. Applied and Environmental Microbiology, 71(9): 5022-5028.

19. Yang, X., Wang, H., He, A., Tran, F. 2018. Biofilm formation and susceptibility to biocides of recurring and transient Escherichia coli isolated from meat fabrication equipment. Food Control, 90: 205-211.

20. Peeters, E., Nelis, H. J., Coenye, T. 2008. Comparison of multiple methods for quantification of microbial biofilms grown in microtiter plates. Journal of Microbiological Methods, 72: 157-165.

21. Myszka, K. and Czaczyk, K. 2011. Bacterial biofilms on food contact surfaces - a review. Pol. J. Food Nutr. Sci., 61: 173180 .

22. Manios, S., Skandamis, P. 2014. Control of Listeria monocytogenes in the Processing Environment by Understanding Biofilm Formation and Resistance to Sanitizers, In: Listeria monocytogenes: Methods and Protocols, Methods in Molecular Biology, vol. 1157, Springer Science Business Media New York.

23. Stepanovic, S., Vukovic, D., Dakic, I., Savic, B., SvabicVlahovic, M. 2000. A modified microtiter-plate test for quantification of Staphylococcal biofilm formation. J. Microbiol. Methods, 40: 175-179.

24. ISO (International Organization of Standardization), 2003 International Organization for Standardization. No. 6888-3. Microbiology of food and animal feeding stuffs - Horizontal methods for the enumeration of coagulase positive staphylococci., Geneva

25. Coffey, B., Anderson, G. 2014. Biofilm Formation in the 96 Well Microtiter Plate, In: Pseudomonas Methods and Protocols, Methods in Molecular Biology, vol. 1149, Springer Science Business Media New York.

26. Tiwari, S., Rajak, S., Mondal, P. M., Biswas, D. 2017. Sodium hypochlorite is more effective than $70 \%$ ethanol against biofilms of clinical isolates of Staphylococcus aureus. American Journal of Infection Control. 46(6): e37-e42.

27. Boakye, Y. D., Osafo, N., Danquah, C. A., Adu, F., Agyare, F. 2019. Antimicrobial Agents: Antibacterial Agents, Antibiofilm Agents, Antibacterial Natural Compounds, and Antibacterial Chemical. Intech Open, 82:1-24.

28. González-Rivas, F., Ripolles-Avila, C., Fontecha-Umaña, F., Ríos-Castillo, A. G., Rodríguez-Jerez, J. J. 2018. Biofilms in the Spotlight: Detection, Quantification, and Removal Methods. Comprehensive Reviews in Food Science and Food Safety, 17: 1261-1276.

29. Kim, M., Park, S. Y., Ha, S. D. 2016. Synergistic effect of a combination of ultraviolet-C irradiation and sodium hypochlorite to reduce Listeria monocytogenes biofilms on stainless steel and eggshell surfaces. Food Control.70:103109.

30. Felipe, V., Breser, M. L., Bohl, L. B., da Silva, E. R., Morgante, C. A., Correa, S., Porporatto , C. 2019. Chitosan disrupts biofilm formation and promotes biofilm eradication in Staphylococcus species isolated from bovine mastitis. Int. J. Biol. Macromol. 126:60-67. 